\title{
Cognition Regulation of Biology Education Students
}

\author{
Bowo Sugiharto $^{1}$, Aloysius Duran Corebima ${ }^{2}$, Herawati Susilo $^{3}$, Ibrohim $^{4}$ \\ ${ }^{1}$ Biology Education Department of Faculty of Teacher Training and Education, Universitas \\ Sebelas Maret, Indonesia \\ ${ }^{234}$ Biology Department of Faculty of Mathematics and Natural Sciences, Universitas Negeri \\ Malang, Indonesia \\ E-mail: bowo@fkip.uns.ac.id
}

\begin{abstract}
Regulation of cognition is a part of metacognition serving as a basic construction of such cognitive skills in controlling learning process as planning, information management strategies, monitoring, debugging strategies, and evaluating. This explorative survey research aimed at comparing the five component skills of regulation. Participants involved in this research were 107 students of third semester of Biology Education (BE) of Faculty of Teacher Training and Education. The participants were purposively selected. The instrument used was the Metacognitive Awareness Inventory (MAI) developed by Schraw and Denisson. Data were analyzed by Anova and were further tested with the least significant difference (LSD). This study concludes that there are significant differences among the five component skills of regulation. Such differences were getting apparent after a post hoc test had been performed, particularly in three skills of regulation. Doing evaluation presents as the lowest skill and it is not significantly different from the subscale of information management strategies. Monitoring is proved as higher skills and is significantly different from the two aforementioned skills. Debugging strategies is higher than monitoring, and planning is the highest one. Both debugging strategies and planning are not significantly different. Such differences give an overview that planning serves as an individual's top priority in learning. In certain condition, he should adapt to or change strategies with regards to the goals set in planning. In reference to such findings, it is suggested that lecturers empower their students by training their skills of regulation such as through online learning and problem-based learning.
\end{abstract}

\section{Keywords: debugging strategies; evaluation, information management strategies; monitoring; planning; regulation of cognition}

\section{INTRODUCTION}

Metacognition was originally introduced as a term related to monitoring and products of the cognitive process [1]. In subsequent development, it is used to refer to cognition about cognition: thinking about your own thinking [2]. Metacognition includes two domains: knowledge of cognition and regulation of cognition [3], [4]. Meanwhile, according to Arthur et al, metacognition falls into metacognitive knowledge and experience [2]. The nature of metacognitive experience is similar to 
that of regulation of cognition. Garrison \& Akyol pointed out the presence of three dimensions of metacognition, namely knowledge of cognition, monitoring of cognition, and regulation of cognition [5].

Regulation of cognition is the major part of metacognition [4], [6]-[9] which refers to the abilities to manage and control an individual's own cognition [3]. It involves a set of mental activities that help students control their learning process [9], and is associated with the monitoring and redirection of one's activities during the course of reading to reach the desired goals [10]. The achievement of the goals which presents as an individual's orientation in learning serves as a foundation of students' independence in learning and is influenced by the regulation of cognition.

Independent learning is defined as a learning strategy that allows students to control their own learning process so that they can use their own strategies, learning resources, and regulation of cognition [11]. This definition reinforces the important role of regulation of cognition. Self-regulated learning is a process consisting of three phases: preparation or planning, task or performance, and adjustment or assessment [12]. Therefore, regulation of cognition contains a number of essential learning skills.

Such essential skills underlie an individual's cognitive performance in learning. The essential skills of regulation include planning, monitoring, and evaluation [3], [9], [13]-[17]. More specifically, regulation of cognition has five component skills: planning, information management strategies, monitoring, debugging strategies, and evaluation [15], [18]-[21].

Planning refers to an individual's activities performed prior to learning activities. In planning activities, a number of components which are likely to be involved or applied in the learning process can be seen. It also covers skills of selecting techniques and allocating resources in learning to affect performance to achieve a cognitive goal. In addition, it includes skills of making prediction before reading, doing strategy sequencing, and allocating time and attention before beginning a task [9].

Monitoring involves an individual's skills of being aware of and assessing his/her own learning and performance. Awareness in experiencing every meaningful learning process means that an individual understands every step/ stage he/she passed through. Furthermore, an individual who is able to monitor well can also measure his/her performance based on every step taken. Monitoring also reflects an individual's skills to master every step taken in learning while remaining to prioritize the goals to be achieved.

Evaluation involves skills of analyzing performance and strategy effectiveness after a learning episode. This implies that an individual is capable of measuring the achievement of his/her determined learning goals. Such skills include making assessment of learning products and efficiency. An example of evaluation is reevaluation of goals and drawn conclusions. The drawbacks of learning procedures to support achievement of goals can be detected by evaluation. Regulation of cognition, therefore, plays a vital role in determining an individual's success.

In context of learning, it was found out that there is relatedness between component skills of regulation and high achievement [22]. The learning experienced by Biology education students requires skills to respond learning sources in the forms of real objects. Different backgrounds of students who were asked to 
encounter relatively-similar problems during a lecture, particularly those related to students' mental processes, are interesting to examine.

The mental processes are focused on aspects of regulation of cognition, particularly whether all component skills of regulation show similar development and whether they can achieve similar outcomes on Biology Education (BE) students. Finding out and measuring knowledge and regulation of cognition is important to help educators improve students' higher-order thinking [23] and to determine academic success [24]. If referring to general context, an improvement of an aspect of regulation is likely to be followed by that of others [9]. However, whether all aspects of regulation of cognition of BE students can be achieved under equivalent circumstances needs to be examined. The present research, therefore, seeks to reveal whether or not such component skills of regulation of BE students as planning, information management strategies, monitoring, debugging strategies and evaluation show a significant difference.

\section{MATERIALS AND METHOD}

The present study belongs to an exploratory survey, a research which attempts to reveal and explain un-manipulated variables of previously-published researches. It involved 107 participants of BE students of Faculty of Teacher Training and Education in one university in Surakarta, Indonesia, which were selected purposively. The survey was done on September 2016.

Examining regulation of cognition of $\mathrm{BE}$ students is important considering that in their learning process, they often encounter real problems and objects at field. The learning took place in the forms of not only lectures, but also practical works. Several students' learning activities equipped them with opportunities to manage and control their own cognitive processes to achieve the goals which had been set up.

An instrument used to measure regulation of cognition was Metacognitive Awareness Inventory (MAI) developed by Schraw \& Dennison (1994) and modified using Likert scale. The use of Likert scale is intended to determine the level or gradation of participants' attitudes. Instrument revealing component skills of regulation comprised of 35 items as displayed in Table I.

TABEL I. DETAILS OF INSTRUMENT OF REGULATION OF COGNITION

\begin{tabular}{|cc|}
\hline Regulation of Cognition & Number of Item \\
\hline P & 7 \\
IMS & 10 \\
M & 7 \\
DS & 5 \\
E & 6 \\
\hline
\end{tabular}

Scores resulted from the measurement of each skill of regulation were converted into scale of 100 . The converted scores were then analyzed using one-way analysis of variance (Anova) proceeded by assumption testing in the forms of Shapiro-Wilk normality test and Levene's test for homogeneity. Once significant difference was found, the least significant difference (LSD) test was administered. The LSD 
provides a clear overview of position of each skill of regulation, and therefore skills with higher/ lower position as well as the significance level of mean difference will soon be found out.

\section{RESULTS AND DISCUSSION}

The five component skills of regulation vary in mean scores and standard deviations. Table II presents description of data on planning $(\mathrm{P})$, information management strategies (IMS), monitoring (M), debugging strategies (DS), and evaluation (E).

TABLE II. DESCRIPTIVE STATISTICS OF REGULATION OF COGNITION

\begin{tabular}{|lrrrrrr|}
\hline $\begin{array}{l}\text { Regulation of } \\
\text { Cognition }\end{array}$ & $\mathrm{N}$ & Minimum & Maximum & Mean & Median & $\begin{array}{r}\text { Std. } \\
\text { Deviation }\end{array}$ \\
\hline P & 107 & 54.29 & 100.00 & 77.9177 & 77.14 & 9.54503 \\
IMS & 107 & 48.00 & 96.00 & 72.9720 & 72.00 & 9.08395 \\
M & 107 & 54.29 & 94.29 & 74.4996 & 74.29 & 8.77253 \\
DS & 107 & 52.00 & 100.00 & 79.2897 & 80.00 & 9.32132 \\
E & 107 & 43.33 & 93.33 & 72.2427 & 73.33 & 9.40352 \\
\hline
\end{tabular}

One assumption test required for Anova is the normality test. This test is used to measure whether the data comes from the normally distributed population, ie following a distribution such as the Gaussian curve pattern Table III summarizes the results of Shapiro-Wilk normality test of data distribution of the five component skills of regulation.

TABLE III. OVERVIEW OF RESULTS OF NORMALITY TEST OF REGULATION OF COGNITION

\begin{tabular}{|lrrr|}
\hline Regulation & \multicolumn{3}{c|}{ Shapiro-Wilk } \\
\cline { 2 - 4 } of Cognition & Statistic & df & Sig. \\
\hline P & 0.984 & 107 & 0.212 \\
IMS & 0.987 & 107 & 0.406 \\
M & 0.983 & 107 & 0.179 \\
DS & 0.977 & 107 & 0.061 \\
E & 0.977 & 107 & 0.066 \\
\hline
\end{tabular}

Table III reveals that the five component skills of regulation have p-value of above 0.05 (sig.>0.05), indicating that the five components skills of regulation were derived from normally distributed population. In addition, the results of test for homogeneity of variance of regulation of cognition (P, IMS, M, DS, and E) are displayed in Table IV. Levene statistic p-value indicated by the above table (0.878) is above 0.05 , meaning that the five component skills of regulation have homogeneous variances. 
TABLE IV. OVERVIEW OF RESULTS OF TEST FOR HOMOGENEITY

\begin{tabular}{|cccc|}
\hline Levene Statistic & df1 & df2 & Sig. \\
\hline 0.300 & 4 & 530 & 0.878 \\
\hline
\end{tabular}

Due to the fulfillment of the two prerequisites, in terms of both normality and homogeneity, hypothesis test using analysis of variance (Anova) was subsequently performed. Table $\mathrm{V}$ indicates that the five component skills of regulation, $\mathrm{P}, \mathrm{IMS}, \mathrm{M}$, DS, and E, significantly differ. To find out which skill of regulation having significant difference, a post hoc test using the least significant difference (LSD) was carried out. With regard to the significant difference in mean scores, an overview of the results of the LSD test was constructed by ordering mean scores from the lowest to the highest. Similar notation was given to skills of regulation having insignificant difference, while different notation was given to those with significant difference. Table VI presents the overview of the results of LSD test.

TABLE V. OVERVIEW OF THE RESULTS OF ANOVA

\begin{tabular}{|lrrrrr|}
\hline & Sum of Squares & df & Mean Square & F & Sig. \\
\hline Between Groups & 4081.177 & 4 & 1020.294 & 11.978 & .000 \\
Within Groups & 45144.987 & 530 & 85.179 & & \\
Total & 49226.164 & 534 & & & \\
\hline
\end{tabular}

TABLE VI. THE OVERVIEW OF POST HOC TEST USING LSD

\begin{tabular}{|lrrrr|}
\hline Regulation of Cognition & Mean & \multicolumn{2}{c|}{$\begin{array}{c}\text { Notation of } \\
\text { LSD }\end{array}$} \\
\hline E & 72.2427 & a & & \\
IMS & 72.9720 & a & & \\
M & 74.4996 & & b & \\
P & 77.9177 & & & c \\
DS & 79.2897 & & c \\
\hline
\end{tabular}

Regulation of cognition serves as an important factor which exerts an influence on performance [25]. Meanwhile, Schwartz pointed out that self-regulation and competent metacognitive control are important factors in improving learning performance [26]. Either high or low metacognitive awareness such as knowledge of cognition and regulation of cognition influences undergraduate students' academic achievement [27]. Another research revealed that self-regulated learning is inseparable from metacognitive skills, particularly regulation of cognition [21]. Such various skills as planning, information management strategies, monitoring, debugging strategies, and evaluation do not undergo similar improvement, but rather they emerge at different outcomes.

Planning and debugging strategies are higher and significantly different from other skills. Such finding is not in line with a previous research which examined preservice teachers' knowledge and regulation of their own thinking and revealed no significant difference by education level on all subscales of MAI except for evaluation [28]. It is not surprising that an individual's learning is mainly determined 
by the plans and targets which have been set. In case that he/she encounters problems in achieving those plans and targets, he/she tends to change his/her strategies.

Planning is not influenced by a condition an individual deals with in learning process. Such fact is supported by, for example, a research carried out by Chen \& Chiu [22] which indicated that no significant difference between planning skills of students treated using collaborative scripts and those of students treated using no collaborative scripts was found. Planning had emerged prior to dynamics of the learning process. It is a part of regulation of cognition which serves as a metacognitive strategy [29]. Such skills present a key to an individual's success in completing an assignment.

Students can put into practice debugging strategies using an appropriate strategy [30]. The presence of various problems which are different from what is expected triggers preservice teachers to change their strategies to reach their goal. According to Sawhney \& Bansal, debugging strategies involve strategies used to correct comprehension and performance errors in learning [27]. Such correction includes not only outcomes, but also sustainability during the learning process.

A learning which trains and stimulates the component skills of regulation has a potential to be improved by Biology education lecturers. The learning focuses not only on transfer of knowledge, but also on life skills and the optimization of cognitive performance. The implementation and the use of technology, for example mobile technology, can enhance regulation of cognition [15] and lead to attractive learning for undergraduate students. Both knowledge of cognition and regulation of cognition simultaneously exert an influence on an individual's abilities in word learning and confidence judgments [31]. A learning which allows to train cognitive monitoring has a potential to improve learning achievement [32].

Independence in learning and metacognitive awareness which belong to regulation of cognition can be trained and the trace can be learned in online learning through Hypermedia Learning Environment [33] since regulation of cognition is generally related to self-monitoring mechanism activated during learning process or decision making [34]. Meanwhile, a research conducted by Hwang et al. found out that self-assessment, journaling, and peer sharing in online learning are able to effectively facilitate students' cognition regulation strategies [32].

A good learning does not only involve transfer of knowledge, but also empowers undergraduate students' cognition. Providing problems to the students appears to be one of effective ways to raise their metacognitive awareness, in term of either knowledge of cognition, or of regulation of cognition. Controlling cognitive awareness and performance can be improved by giving students opportunities to reflect their own learning process and outcomes. Enhancing students' independence in learning is effective to raise their awareness in monitoring their cognitive performance. One way to make it happen is by making use of online learning.

Online learning is able to train students' cognitive control. The application of mobile technology in online learning have a significant impact on cognitive regulation [15]. Student's initiative in utilizing technology in online learning activities becomes the trigger for student's regulation of cognition. In addition, the demands of using skills in technology operating can stimulate the development of regulation of cognition. The application of online learning combined with face to face learning, commonly called blended learning. Blended learning has been 
implemented with a variety of designs and has shown positive results to be considered in the learning process [35].

In addition, Problem Based Learning (PBL) also has the potency to develop regulation of cognition. Tan stated, that $\mathrm{PBL}$ is the learning models through the presence of ill structured problem [36] to empower thinking ability, learn, and apply problem solving to gain deeper knowledge. PBL is identified to develop problemsolving strategies and knowledge-based disciplines by providing problem-solving challenges [37]. The presence of the problem that must be solved by students become the media for the development of regulation of cognition ability.

\section{CONCLUSION AND RECOMMENDATION}

The research concludes that there are differences among the five component skills of regulation of Biology Education students. The lowest subscale is evaluation, which is not significantly different from information management strategies. Higher subscale is represented by monitoring, which is significantly different from evaluation and information management strategies. Higher subscale than monitoring is debugging strategies, and the highest one is planning. Debugging strategies and planning are not significantly different.

In reference to the results of the research, it is recommended to Biology Education lecturers to perform learning by empowering students' component skills of regulation. Regulation of cognition can be trained by providing problems to students and improving their independence in learning. Such learning which uses real-world problems is regarded a challenge which trains students' cognitive skills and awareness. Their independence in learning can be improved, for example, by carrying out online learning.

\section{REFERENCES}

[1] J. H. Flavell, "Metacognition and cognitive monitoring: A new area of cognitive-developmental inquiry.," Am. Psychol., vol. 34, no. 10, pp. 906-911, 1979.

[2] J. Arthur, T. Grainger, and D. Wray, Learning to Teach in the Primary School. New York: Routledge Taylor \& Francis Group, 2006.

[3] C. M. McMahon, H. A. Henderson, L. Newell, M. Jaime, and P. Mundy, "Metacognitive Awareness of Facial Affect in Higher-Functioning Children and Adolescents with Autism Spectrum Disorder,” J. Autism Dev. Disord., vol. 46, no. 3, pp. 882-898, 2016.

[4] G. Schraw and R. S. Dennison, "Assessing Metacognitive Awareness," Contemp. Educ. Psychol., vol. 19, no. 4, pp. 460-475, 1994.

[5] D. R. Garrison and Z. Akyol, "Toward the Development of a Metacognition Construct for Communities of Inquiry,” Internet High. Educ., vol. 24, pp. 66-71, 2015.

[6] P. W. Airiasian, K. A. Cruikshank, R. E. Mayer, P. R. Pintrich, J. Raths, and M. C. Wittrock, A Taxonomy for Learning, Teaching and Assessing: A Revision of Bloom's Taxonomy of Educational Outcomes: Abridge Edition. New York: Longman, 2001.

[7] A. D. Corebima, "Metacognitive Skill Measurement Integrated In Achievement Test," State Univ. Malang, 2009. 
[8] A. Ma and P. D. Baranovich, "Promoting Self-Regulation in Vocabulary Learning among Chinese EFL Learners : A Needs Analysis,” vol. 24, no. 1, pp. 137-146, 2015.

[9] G. Schraw, "Promoting General Metacognitive Awareness," Instr. Sci., vol. 26, no. 1-2, pp. 113-125, Mar. 1998.

[10] D. R. Cross and S. G. Paris, "Developmental and Instructional Analyses of Children's Metacognition and Reading Comprehension," J. Educ. Psychol., vol. 80, no. 2, pp. 131-142, 1988.

[11] P. R. Pintrich, "The role of motivation in promoting and sustaining self-regulated learning," Int. J. Educ. Res., vol. 31, no. 6, pp. 459-470, 1999.

[12] M. T. Mohtadi, A. Hajami, and H. Allali, "Pedagogical Agent for Metacognitive Scaffolding in Interactive Learning Environments," in IEEE, 2014, pp. 652-656.

[13] A. Akin, R. Abaci, and B. Çetin, "The validity and reliability of the Turkish version of the metacognitive awareness inventory,” Educ. Sci. Theory Pract., vol. 7, no. 2, pp. 671-678, 2007.

[14] S. Javid, H. R. Alavi, and M. F. Pour, "The Relationship Between Religious Commitment with Meta-Cognitive Skills and Philosophical Mindedness of the Graduate Students of Kerman City Universities in the Academic Year 2011-2012," J. Relig. Health, vol. 54, no. 3, pp. 943-953, Dec. 2013.

[15] C. B. Lee, "Exploring the Relationship between Intention to Use Mobile Phone as a Visualization Tool and Regulation of Cognition," Comput. Educ., vol. 60, no. 1, pp. 138-147, 2013.

[16] R. A. Sperling, B. C. Howard, L. A. Miller, and C. Murphy, "Measures of children's knowledge and regulation of cognition," Contemp. Educ. Psychol., vol. 27, no. 1, pp. 51-79, 2002.

[17] F. Teng, "Immediate and Delayed Effects of Embedded Metacognitive Instruction on Chinese EFL Students' English Writing and Regulation of Cognition," Think. Ski. Creat., vol. 22, pp. 289-302, 2016.

[18] H. Byun, J. Lee, and F. A. Cerreto, "Relative Effects of Three Questioning Strategies in Illstructured, Small group Problem solving," Instr. Sci., vol. 42, no. 2, pp. 229-250, Apr. 2013.

[19] K. R. Muis, P. H. Winne, and D. Jamieson-Noel, "Using a multitrait-multimethod analysis to examine conceptual similarities of three self-regulated learning inventories," Br. J. Educ. Psychol., vol. 77, no. 1, pp. 177-195, 2007.

[20] G. Schraw and R. S. Dennison, “The Effect of Reader Purpose on Interest and Recall,” J. Lit. Res., vol. 26, no. 1, pp. 1-18, 1994.

[21] G. Wesiak et al., "Iterative Augmentation of a Medical Training Simulator: Effects of Affective Metacognitive Scaffolding," Comput. Educ., vol. 76, pp. 1-27, 2014.

[22] C.-H. Chen and C.-H. Chiu, "Collaboration Scripts for Enhancing Metacognitive Self-regulation and Mathematics Literacy," Int. J. Sci. Math. Educ., pp. 1-18, 2015.

[23] B. M. Scott and M. Levy, "Metacognition: Examining the Components of a Fuzzy Concept," Educ. Res. eJournal, vol. 2, no. 2, pp. 120-131, 2013.

[24] H. Tok, H. Özgan, and B. Döş, “Assessing Metacognitive Awareness and Learning Strategies As Positive Predictors for Success in a Distance Learning Class,” Mustafa Kemal Üniversitesi Sos. Bilim. Enstitüsü Derg., vol. 7, no. 14, pp. 123-134, 2010.

[25] B. J. Knox, R. G. Lugo, O. Josok, K. Helkala, and S. Sutterlin, “Towards a Cognitive Agility Index: The Role of Metacognition in Human Computer Interaction," in International Conference on Human-Computer Interaction, 2017, vol. 617, pp. 330-338.

[26] L. K. Son and B. L. Schwartz, "The Relation Between Metacognitive Monitoring and Control," in Applied Metacognition, Cambridge University Press, 2009, pp. 15-38.

[27] N. Sawhney and S. Bansal, "Metacognitive Awareness of Undergraduate Students in Relation to their Academic Achievement," Int. J. Indian Psychol., vol. 3, no. 1, pp. 107-114, 2015. 
[28] C. B. Lee, T. Teo, and C. S. Chai, "Profiling Pre-service Teachers' Awareness and Regulation of Their Own Thinking: Evidence from an Asian Country," Teach. Dev., vol. 14, no. 3, pp. 295306, 2010.

[29] E. Panahandeh and S. E. Asl, "The Effect of Planning and Monitoring as Metacognitive Strategies on Iranian EFL Learners' Argumentative Writing Accuracy," Procedia - Soc. Behav. Sci., vol. 98, pp. 1409-1416, 2014.

[30] A. Chatzipanteli, N. Digelidis, and A. G. Papaioannou, "Self-Regulation, Motivation and Teaching Styles in Physical Education Classes: An Intervention Study," J. Teach. Phys. Educ., vol. 34, no. 2, pp. 333-344, 2015.

[31] F. Teng, "The Effects of Task-induced involvement Load on Word Learning and Confidence Judgments Mediated by Knowledge and Regulation of Cognition," Educ. Sci. Theory Pract., vol. 17, no. 3, pp. 791-808, 2017.

[32] W.-Y. Hwang, J.-L. Hsu, R. Shadiev, C.-L. Chang, and Y.-M. Huang, "Employing SelfAssessment, Journaling, and Peer Sharing to Enhance Learning from an Online Course," J. Comput. High. Educ., vol. 27, pp. 114-133, 2015.

[33] M. T. Mohtadi, A. Deraoui, H. Allali, and A. Hajami, "Trace-based System For Metacognitive Behavior in Online Learning Activity," in 5th International Conference on Multimedia Computing and Systems (ICMCS), 2016, 2016, pp. 1-4.

[34] E. Mokos and S. Kafoussi, "Elementary Students' Spontaneous Metacognitive Functions in Different Types of Mathematical Problems," J. Res. Math. Educ. REDIMAT -Journal ofResearch Math. Educ., vol. 2, no. 2, pp. 242-267, 2013.

[35] R. Alebaikan and S. Troudi, "Blended Learning in Saudi Universities: Challenges and Perspectives," Res. Learn. Technol., vol. 18, no. 1, 2010.

[36] O. S. Tan, Enhancing Thingking through Problem Based Learning Approaches (International Perspectives). Singapore: Thomson Learning Asia, 2004.

[37] J. Jolly and C. Jacob, “A Study of Problem Based Learning Approach for Undergraduate Students," Asian Soc. Sci., vol. 8, no. 15, pp. 157-164, 2012. 